\title{
Da terra das sombras à terra dos sonhos: o sagrado em $O$ beijo da palavrinha de Mia Couto
}

\author{
Cristiano Camilo Lopes ${ }^{1}$
}

RESUMO: Nosso objetivo é identificar a presença do sagrado na obra $O$ beijo da palavrinha, de Mia Couto. Como um substrato para mitos, ritos e arquétipos, o sagrado tem permeado a literatura, revelando o homem e sua relação com suas crenças, além de evidenciar-se como um elemento essencial e norteador do ser que o aceita. Através da análise, percebemos que a experiência sobrenatural com o sagrado não está vinculada estritamente a questões religiosas, mas volta-se para o homem e sua vivência.

ABSTRACT: In this paper we aim to analyze the presence of the sacred in the work $O$ beijo da palavrinha, by Mia Couto. As a basis for myths, rites and models, the sacred has been used in the literature, by revealing the mankind and its relation with its beliefs. In several literary works the sacred has been highlighted as an essential element and a guide for those who accept it. According to our analysis, we ask to realize the supernatural experience with sacred is not strictly linked to religious questions, but it refers to the mankind and its life.

PALAVRAS-CHAVE: Sagrado; Mia Couto; Mito; Eterno Retorno

KEYWORDS: Sacred; Mia Couto; Myth; Eternal Return

O período atual é marcado por vários fatores que o caracterizam como uma época de "busca", iniciada desde a modernidade. A partir desse marco, a ciência se apresentou com vislumbres de esperança em promessas não mais embasadas no sagrado, como ocorreu até o século XVI: “[...] os teólogos e filósofos compartilhavam do pressuposto de que Deus é a base fundamental do conhecimento verdadeiro. Por isso, conhecer a Deus significava conhecer a própria verdade.”(MADUREIRA, 2008, p. 107).

Instaurou-se, portanto, um período de mudanças de visão, de tendências e de atitudes que foram bem expostas pelo fisico Fritjof Capra em sua obra O Ponto de Mutação. Na obra em questão, o autor

\footnotetext{
${ }_{1}^{1}$ Mestrando em Estudos Comparados de Literaturas de Língua Portuguesa, FFLCHUSP. Pesquisa: Da terra das sombras à terra dos sonhos: o espaço sagrado na literatura para crianças e jovens. Contato: cristianoclopes@usp.br
} 
justifica que as transformações ocorridas na modernidade têm sua base no contraste entre a visão mecanicista e fragmentária de Descartes e Newton com as teorias da relatividade e da física quântica:

[...] são facetas diferentes de uma só crise, que é, essencialmente uma crise de percepção [...] ela deriva do fato de estarmos tentando aplicar os conceitos de uma visão de mundo obsoleta a visão de mundo mecanicista da ciência cartesiana-newtoniana a uma realidade que já não pode ser entendida em função desses conceitos. Vivemos hoje num mundo globalmente interligado, no qual os fenômenos biológicos, psicológicos, sociais e ambientais são todos interdependentes. (CAPRA, 2006, p. 14).

Além disso, a tecnociência passou a responder pelo avanço dos meios de comunicação de massa, da informática, da eletrônica, que fazem da pós-modernidade uma época de consumo. Assim, predomina em nossa cultura o veloz, o efêmero, o descartável, o instável, o "novo". Todos esses elementos fazem do homem moderno um ser "a imagem e semelhança dos produtos que consome.” (QUEIROZ, 2006).

Dessa forma, nossa proposta é apresentar o sagrado como um elemento que proporciona ao homem um olhar interno e, ao mesmo tempo, transcendental. A partir desse olhar, o ser humano torna-se hábil para dialogar com as propostas contemporâneas sem perder de vista o essencial para sua vivência.

\section{O Retorno do Sagrado}

Com seu apelo à luz da razão e do avanço do progresso técnicocientífico, a modernidade afastou o homem da possibilidade de apegarse ao sagrado. Contudo, a história da filosofia nos mostra que a própria razão moderna entrou em crise, pois não conseguiu responder às questões humanas. Com isso, o homem tem se mostrado como um ser à procura de sentido, valor e esperança, elementos que orientem sua existência. Nesse caso, a razão parece não proporcionar tais elementos no interior do homem. 
Assim, julgamos necessário refletir sobre o eterno retorno do sagrado a fim de podermos identificar sua presença na pósmodernidade.

Entendemos por eterno retorno o ciclo do mito reatualizado através do rito, para que ocorra a renovação do mundo. Nessa perspectiva, cada mudança temporal ou fim de determinados momentos com suas crenças não deve representar a incerteza, pelo contrário, deve apontar para a "certeza de um novo começo" (ELIADE, 2007, p. 72). marca do eterno retorno. Em outras palavras, é a escatologia apontando para a cosmogonia.

Por meio do eterno retorno, podemos delinear que há uma certa "mobilidade" do sagrado, ou seja, ainda que seja periodicamente deixado, ele se configura na vida atual:

A mobilidade da origem do Mundo traduz a esperança do homem de que seu Mundo estará sempre lá, mesmo que seja periodicamente destruído no sentido estrito do termo. Solução ou desespero? Não, pois a idéia de destruição do Mundo não é, no fundo, uma idéia pessimista. Por sua própria duração, o Mundo degenera e se consome; eis por que deve ser simbolicamente recriado todos os anos. (ELIADE, p. 72).

Gianni Vattimo, (DERRIDA,2004) quando afirma que a presença do sagrado em nossa época não é um fato que ocorre acidentalmente, sugere que o retorno do sagrado é impulsionado por elementos como o pavor frente ao perigo nuclear, às ameaças no campo ecológico, à manipulação genética. Tudo isso gera, assim, o medo da perda do sentido de existência e o tédio que acompanha o consumismo.

Ressaltamos que a pós-modernidade não exclui a razão, contudo requer algo mais. Nesse sentido, o sagrado se apresenta como resposta para o indivíduo. Imposta com uma nova configuração, denominada sagrado selvagem.

\section{O Sagrado Selvagem}


A presença do sagrado em nossos dias se manifesta de forma mais espontânea. Por isso, esse elemento assume um caráter inovador, com uma nova configuração, denominada, pelo sociólogo francês Roger Bastide, sagrado selvagem: "[...] esse sagrado que vemos novamente surgindo na cultura e na sociedade de hoje quer-se um sagrado selvagem". Trata-se do sagrado com formas espontâneas, livres da institucionalização: "[...] situa-se no domínio do imaginário, não no da memória --, mas para, ainda assim, deles extrair tudo aquilo que poderíamos chamar de pedagogia da selvageria." (2006, p.251).

O sagrado possui uma forma privatizada uma vez que se apresenta entregue às vivências individuais do homem. Nele:

o sistema ideacional de valores é profundamente diferente. Sustenta que a verdadeira realidade se situa além do mundo material [...] e que o conhecimento pode ser obtido através da experiência interior. Subscreve valores éticos absolutos e padrões sobre-humanos de justiça, verdade e beleza. (CAPRA, p. 29).

Essa privatização da experiência humana remete a outro aspecto do sagrado selvagem: a alteridade do sagrado. Essa alteridade:

[...] é o dom humano que faz a pessoa se lançar em busca do "plenamente outro" e catalisa suas disposições referentes ao sagrado. Corresponde à sensibilidade de intuir o mistério da existência e de procurar respostas aos questionamentos sobre seu sentido. Ainda que possa não se manifestar em todas as pessoas, é a capacidade essencialmente humana de apreender a dimensão sagrada do mundo. (TESCAROLO, 2005, p.151)

De acordo com Bastide, a busca pelo outro é impulsionada pela passagem de uma sociedade orgânica a uma sociedade anômica. Essa transformação se deu mediante o enfraquecimento do controle da sociedade global em decorrência das mutações sofridas pelas: "infraestruturas dessa sociedade rural e pré-industrial para uma sociedade urbana e industrializada." (BASTIDE, p. 260).

Esse estado de anomia da sociedade trouxe consequências na vivência interior do homem, como a solidão, que, por conseguinte, fez que a busca pela alteridade se tornasse mais intensa: “[...] uma 
'alteridade' nova capaz de desalterar uma sede que ele não consegue extinguir [...]"(BASTIDE, p.268).

Dessa forma, o sagrado selvagem se manifesta, também, como abertura do homem para os outros e promove a identificação entre os homens por meio das atividades da ação comunicativa apoiadas pelo pensar, querer e julgar do espírito. Nesse sentido, o homem passa a considerar o valor do próximo assumindo:

[...] sentimento de respeito, 'um papel muito importante na experiência ética dos valores e, de modo especial, na experiência ética dos valores e, de modo especial, na experiência religiosa da pessoa, área em que a realidade antropológica do mistério humano é convocada em toda sua profundidade. (TESCAROLO, p. 158).

Portanto, ressaltamos que o sagrado tem como marca a experiência interior e, nesse aspecto, a sua presença na literatura serve de grande contribuição para o diálogo com as marcas instauradas na modernidade bem como em suas propostas atuais. Essa contribuição do sagrado se expressa no respeito, como "cuidado", "atenção", “preocupação”, “estima”, “admiração”, "preocupação com o outro”, e “consideração" e "valorização do outro".

Reforçamos, ainda, que o sagrado faz que as resistências entre o homem, o mundo e os diferentes níveis de realidade e de percepção sejam superadas, pois ele se apresenta como

um vínculo orgânico universal que conecta em rede dinâmica essa pessoa e esse mundo com a perene certeza da existência de um terceiro que transcende sempre essa relação, mas que a integra e justifica o mistério humano, constituindo o sagrado." (TESCAROLO, p. 158).

O beijo da palavrinha ${ }^{2}$, publicado em 2006, é o segundo livro destinado a crianças e jovens do autor moçambicano Mia Couto. A obra

2 COUTO, Mia. O beijo da palaurinha Rio de Janeiro: Língua Geral, 2006. Nossa indicação dos números de páginas serve de orientação ao leitor pois, o livro não apresenta numeração de páginas em sua publicação. 
faz parte da coleção Mama África, publicada pela Língua Geral Livros, com o objetivo de trazer a recriação dos contos tradicionais africanos.

Nela, parte do patrimônio africano é retomado, fornecendo ao leitor o trânsito temporal: a concepção da tradição oral na modernidade. Não se trata de pólos opostos (tradição e modernidade), mas de uma sociedade que se circunscreve fundamentalmente tradicional e fundamentalmente moderna.

O livro aborda questões existenciais de uma forma sensível e contribui para a formação integral de seus leitores. Para isso, a obra apresenta um enredo conciso, simples e claro. As personagens se apresentam com nomes próprios que remetem a um significado Maria Poeirinha, Zeca Zonzo e Jaime Litorânio. Além disso, o segundo nome das personagens indica a trajetória de cada um ao longo da narrativa.

$O$ beijo da palavrinha retrata a saga existencial da personagem principal Maria Poeirinha, uma menina que vivia em uma aldeia no interior e em condições de pobreza: "[...] viviam numa aldeia tão interior que acreditavam que o rio que ali passava não tinha nem fim nem foz." (COUTO, 2006, p. 3).

Essa vida no interior da aldeia é caracterizada pela miséria, pela pobreza, pela fome, pela seca e, principalmente, pela ausência do mar. É digno de nota que Mia Couto ressalta o termo tão interior (grifo nosso), sugerindo uma descrição não apenas das condições geográficas e sociais da aldeia. Ao empregar o advérbio tão, o autor remete para o interior de Maria Poeirinha. Sua alma, seu espaço interior, seu íntimo, marcados pela ausência: "Era uma vez uma menina que nunca vira o mar ".(COUTO,p.3).

Quando Maria Poeirinha se lembrava do espaço em que vivia, percebia a discrepância do seu contexto em relação à realidade das águas: "Na miséria em que viviam, nada destoava. Até Poeirinha tinha sonhos pequenos [...] mas depressa ela saía do sonho pois seus pés descalços escaldavam na areia quente. E o rio secava, engolido pelo chão." (COUTO, p.7). 
Maria Poeirinha tinha um irmão chamado Zeca Zonzo que, como o segundo nome sugere, vivia sempre à mercê da fantasia e da imaginação: "[...] era desprovido de juízo. Cabeça sempre no ar, as idéias lhe voavam como balões em final de festa" (COUTO, p.4). Embora vivendo nas mesmas condições precárias da aldeia interiorana, Zeca Zonzo não se deixou marcar por essas condições e instigava a irmã a viver por meio dos sonhos, da fantasia e da imaginação.

Maria Poeirinha, às vezes, sonhava com a água, pensava que nela viveria outra realidade, bem diferente da sua vida interiorana: "Às vezes sonhava que ela se convertia em rio e seguia com passo lento, como a princesa de um distante livro, arrastando um manto feito de remoinhos, remendos e retalhos." (COUTO, p.4). Trata-se da oscilação entre sombra e sonho, entre espaço profano e espaço sagrado.

Contudo, para que essa transição aconteça, é necessário um 'portal'(COUTO, p. 7), um elemento que sirva de passagem entre os dois mundos. Dessa forma, a obra apresenta uma terceira personagem: o tio Jaime Litorânio. Como seu segundo nome sugere, ele ressalta a necessidade da água para a vida. No contexto africano, a figura do ancião representa a tradição. Ele é o responsável pelas rodas e reuniões com o propósito de perpetuar a sabedoria. Assim, o tio Jaime Litorânio enfatiza a necessidade de se conhecer o mar: "[...] o tio Jaime Litorânio que achou grave que os seus familiares nunca tivessem conhecido os azuis do mar. Que a ele o mar lhe havia aberto a porta para o infinito." (COUTO,p. 8- 9).

O mar simboliza a dinâmica da vida, representa o sagrado. É o lugar do mergulho de salvação por meio de morte simbólica: "[...] centro de vida, meio de purificação, centro de regenerescência [...] infinidade dos possiveis [...] fonte de todas as coisas, manifesta o transcendente e deve ser, em conseqüência, considerada como uma hierofania [...]" (CHEVALIER, 2007, p. 15).O tio acentua a necessidade dessa imersão de uma forma singular: "[...] Quem nunca viu o mar não sabe o que é chorar!" (COUTO, p. 11). 
Maria Poeirinha adoece e passa a esmorecer sem o mar. Dessa maneira, tio Jaime Litorânio propõe uma 'viagem salvadora' até o litoral, pois acreditava que sua doença era oriunda da falta de contato com o mar. Porém, o físico da menina não aguentaria o desgaste da viagem.

Coube ao irmão Zeca Zonzo proporcionar a viagem salvadora para a menina enferma. Ele escreve a palavra mar em uma folha em branco e, ao passar a ponta dos dedos de Maria Poeirinha sobre as letras, levou a menina, pela imaginação, ao mar.

E assim letra a letra, o irmão levou a irmã a descobrir: “- É um 'm'. E sorriram os dois [...] - É isso, manito. Essa letra é feita por ondas. Eu já as vi no rio.” (COUTO, p. 20).

Logo em seguida, Maria Poeirinha toca a letra a: “- Essa a seguir é um 'a'. É uma ave, uma gaivota pousada nela própria, enrodilhada perante a brisa fria." (COUTO, p. 20). A gaivota é símbolo de luz, que rompe com a noite escura e inicia um novo amanhecer. Era o contato com o sagrado no espaço trazendo luz e rompendo com o profano: “ a gaivota é proprietária da luz do dia "(CHEVALIER, p. 456).

Por fim, vem a letra r: “- É uma letra tirada da pedra. É o 'r' da rocha."(COUTO, p. 21). Pedra indica que o divino desceu para manifestar-se entre os homens: "a pedra apresenta o movimento de subida e descida [...] ela desce do céu; transmutada, ela se ergue em sua direção [...] símbolo de liberdade” (CHEVALIER, p. 656).

Dessa forma:

as curvas das vagas oceânicas através dos contornos do m; o vôo da liberdade criadora, por intermédio da letrinha a, ave voando por entre a cosmicidade das palavras; a dureza das rochas, simbolo da resistência e da insaciabilidade dos desejos humanos por meio do $r$, cujas arestas arranharam-lhe a sensibilidade e acenderam-lhe a força ígnea da linguagem. (SECCO, 2007, p. 175).

Maria Poeirinha fora beijada pelo mar: "- Eis a mana Poeirinha que foi beijada pelo mar." (COUTO, p.26). Nessa viagem, a personagem transcende nos espaços, pelo portal da imaginação, adentrando no espaço sagrado. De acordo com Carmen Lucia Tindó Secco, a alegoria 
do beijo remete a um sentido espiritual que, em nosso trabalho, pode ser chamado de sagrado: "Da boca sai o beijo, assim como dela também se desprende o sopro vital que se transforma no verbo criador, no barro da palavra." (SECCO, p. 175).

O nome Poeirinha sugere origem e fim. O homem, diz a Bíblia, veio do pó e para o pó voltará - "poeira cósmica" (SECCO, p. 175). Dessa forma, o nome Poeirinha abarca a idéia de soltura, saída, prontidão para a ida, rumo ao novo: "[...] poeira é símbolo de força criadora $[\ldots]$ simboliza o abandono total do passado, uma ruptura completa, uma negação de tudo o que representava essa poeira: pátria, família, amizade, etc." (CHEVALIER, p. 727).

Temos, então, o espaço sagrado: o mar. Maria Poeirinha foi envolvida num beijo e, arrastada pelo mar, deixou para trás a doença e a miséria: "[...] para renascer como poeira cósmica, origem-explosão do Cosmos, matriz permanente da imaginação criadora." (SECCO, p. 175).Saiu do território profano para o centro do mundo no espaço sagrado. Foi o contato com o assombroso e o misterioso que promoveu a transformação: "Poeirinha que foi beijada pelo mar. E se afogou numa palavrinha." (COUTO, p. 24).

O sagrado, portanto, à luz da análise, pode ser considerado como elemento essencial e norteador na formação do ser. Através da cosmogonia e do mito do eterno retorno, o espaço sagrado evidencia uma nova experiência no interior do homem, instaurando, assim, a mudança do caos ao cosmos. Nesse sentido, estar no espaço sagrado é estar em contato com o transcendente e com a própria identidade, pois nele o homem sente-se seguro por ter sua identidade resgatada, sendo desafiado a se aventurar no conhecimento de si e do mundo.

Nessa perspectiva, a Literatura para Crianças e Jovens se apresenta como um elo perfeito entre o sagrado e o homem, proporcionando a experiência com a realidade e permitindo que a criança a decodifique a seu modo. O leitor, portanto, é formado para a vida trazendo a vida real para a vida interior. 


\section{Referências bibliográficas}

BASTIDE, Roger. O Sagrado Selvagem e outros ensaios. Trad. Dorothée de Bruchard.São Paulo: Companhia das Letras, 2006.

CAPRA, Fritjof. O Ponto de Mutação; a ciência, a sociedade e a cultura emergente. Trad. Álvaro Cabral. 26.ed., São Paulo: Cultrix, 2006.

CHEVALIER, Jean; GHEERBRANT, Alain. Dicionário de Símbolos Trad. Vera da Costa e Silva, Raul de Sá Barbosa, Angela Melim, Lúcia Melim. 21.ed., Rio de Janeiro: José Olympio, 2007.

COUTO, Mia. O beijo da palaurinha Rio de Janeiro: Língua Geral, 2006.

DERRIDA, Jacques; VATTIMO, Gianni, (Orgs.). A Religião Trad. Tadeu Mazzola Verza, São Paulo: Estação Liberdade, 2004.

ELIADE, Mircea. Mito e Realidade Trad. Pola Civelli. 6.ed., São Paulo: Perspectiva, 2007.

MADUREIRA, Jonas. Filosofia São Paulo: Vida Nova, 2008.

QUEIROZ, José J. Deus e Crenças Religiosas no Discurso Filosófico Pósmoderno; linguagem e religião REVER, ISSN: 1677-1222, São Paulo, 2006.

SECCO, Carmen Lucia Tindó (Org.). Ensaio Sobre Literatura Infantil de Angola e Moçambique; Entre Fábulas e Alegorias Rio de Janeiro: Quartet, 2007.

TESCAROLO, Ricardo. A Escola como Sistema Complexo; a ação, o poder e o sagrado São Paulo: Escrituras, 2005. 